Military Technical College

Kobry El-Kobbah,

Cairo, Egypt.

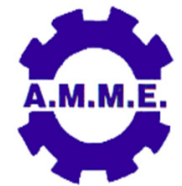

$18^{\text {th }}$ International Conference

on Applied Mechanics and

Mechanical Engineering.

\title{
THE EFFECT OF HEAT TREATMENT ON MICROSTRUCTURE AND MECHANICAL PROPERTIES OF A356/ZrO ${ }_{2}$ NANO REINFORCED COMPOSITES
}

\author{
H. Tiwery ${ }^{1}$, W. Hoziefa ${ }^{2}$, Adel B. El-Shabasy ${ }^{3}$ and I. El-Mahallawi ${ }^{4}$
}

\begin{abstract}
Aluminum A356 alloys have several interesting properties to be used in automobile and aircraft industries. Recent studies have shown that the properties of cast aluminum alloys are modified by the insertion of reinforcement nanoparticles. This study investigates the microstructure and mechanical properties of $\mathrm{ZrO}_{2}$ nanoreinforced A356 alloy in T6 heat treated condition. Some samples of as cast monolithic A356 and $3 \% \mathrm{ZrO}_{2}$ nanoparticles $(30 \mathrm{~nm})$ reinforced $\mathrm{A} 356$ were prepared by stir casting from the semi-solid state followed by T6 heat treatment process. The samples were solution treated at temperature of $550^{\circ} \mathrm{C}$ for 2 hours followed by aging at different temperatures $\left(170^{\circ} \mathrm{C} \& 180^{\circ} \mathrm{C}\right)$, for different aging time (2hr,4hr\&6hr). The results obtained in this work showed enhancement in the mechanical properties (ultimate strength, ductility and hardness). The as cast samples showed values of $119 \mathrm{MPa}, 4.5 \%$ \& $23 \mathrm{HRB}$, respectively, while the $3 \% \mathrm{ZrO}_{2}$ reinforced samples showed the values of $165 \mathrm{MPa}, 4.7 \%$ \&60 HRB, respectively. After T6 heat treatment, the same values changed to $198 \mathrm{MPa}, 6.4 \%$ \&70HRB, respectively for the nanoreinforced samples. The microstructure morphology was changed from lamellar eutectic structure to spheriodized eutectic structure.
\end{abstract}

\section{KEY WORDS}

Al-Si alloys, Nanocomposite, Aging.

1 Department of Design and production Engineering. Faculty of Engineering, Ain Shams University, P.O. Box 11517, Cairo, Egypt. Email: hasssn.mohamed.201@gmail.com

2 Department of Metallurgy, Mining \& Petroleum Engineering, Faculty of Engineering, AlAzhar University, P.O. Box 11884, Cairo, Egypt. Email: hoziefa2012@outlook.com. hoziefa21012@azhar.edu.eg

3 Department of Design and production Engineering. Faculty of Engineering Ain Shams University, P.O. Box 11517, Cairo, Egypt. Email: adel.elshabasy@eng.asu.edu.eg

4 Department of Metallurgical Engineering, Faculty of Engineering, Cairo University, P.O. Box, 12316 Giza, Egypt. Email: saiman@eng1.cu.edu.eg; ielmahallawi@bue.edu.eg 


\section{INTRODUCTION}

Aluminum and its alloy are used in many industrial applications, due to their excellent properties, such as high strength-to-weight ratios, high thermal conductivity, good corrosion properties and excellent workability [1-5]. The use of Al-Si-Mg alloys, in particular, is attractive to the automotive industry, due to lightweight and reasonable strength after ageing treatment [6]. The structure of as-cast A356 alloys consists of coarse primary a-Al dendrites and acicular-shaped eutectic silicon, which decreases the mechanical properties and limits its industrial applications. The mechanical properties are usually controlled by controlling the microstructures of the alloys $[7,8]$.

The commonly used methods for improving the mechanical properties of the Al-Si casting alloys include grain refinement, modification of structure and heat treatment. Grain refinement is done by adding Ti-B or Ti-C based grain refiners into the melt to refine the grain size of the casting into fine-Equiaxed structures [9-10]. Further improvement of mechanical properties is achieved by heat treatment. Heat treatment of these alloys leads to successive precipitation of reinforcing precipitates, depending on the alloying additions. The successive precipitation sequence in Al-Si alloys to which $\mathrm{Mg}$ is added is $\beta S S S \rightarrow \beta^{\prime \prime} \rightarrow \beta^{\prime} \rightarrow \beta\left(\mathrm{Mg}_{2} \mathrm{Si}\right)$ ) and in Al-Si-Mg alloys with $\mathrm{Cu}$ addition is aSSS $\rightarrow \theta^{\prime \prime} \rightarrow \theta^{\prime} \rightarrow \theta\left(\mathrm{CuAl}_{2}\right)$; where, $\beta S S S$ and aSSS is the supersaturated solid solution. The complete precipitation sequence can only occur when the alloy is aged at temperatures below the GP zone solves. The mechanism of the transformation sequence usually involves heterogeneous nucleation at the sites of earlier products, resulting in fine and uniform precipitate dispersions [11-12]. Heat-treatable aluminum alloys are those whose mechanical properties may be improved by means of a specific heat treatment. The T6 heat treatment process involves three stages, namely, solution heat treatment, quenching and aging. The purpose of the solution heat treatment is to place the maximum amount of hardening solutes, such as Mg, into solid solution in the aluminum matrix [13-20]. T6 is the most used heat treatment for the Al-Si-Mg alloy, and it consists of solution heat treatment and artificial ageing [16]. Heat treatment results enhancement in the casting mechanical and microstructure properties [17-19]. Heat treatment is also carried out to obtain optimum combination of ductility and strength in Al-Si-Cu-Mg alloys, by solution treatment, quenching and artificial aging [20].

During the last ten years many researchers [21-31] have investigated and reported the beneficial effects of adding nanoparticles to A356 alloy with respect to microstructural refining and mechanical properties enhancement. However, the main problem reported by almost all researchers was the tendency of the nanoparticles to agglomerate. This problem has been approached in literature via different techniques regarding the pretreatment of the nanoparticles and the control of their addition parameters. The authors have investigated the addition and pretreatment conditions in a previous work [31], from which it was shown that the treatment and feeding technique of the nanoparticles have a strong effect on the efficiency of the nanodispersed strengthening of A356 cast aluminum alloy. There is lack in literature on the study of the effect of T6 heat treatment on the final properties of this alloy, therefore the aim of the present investigation is to study the microstructure and mechanical properties of the as cast and T6 heat treated A356 alloy reinforced with $\mathrm{ZrO}_{2}$ nanoparticles. 


\section{EXPERIMENTAL WORK}

\section{Material and Manufacturing Process}

The matrix alloy used for this study is A356 alloy, which has the chemical composition shown in Table1, in weight percentage. $\mathrm{ZrO}_{2}$ particles of $30 \mathrm{~nm}$ sizes were added as the reinforcement shown in Fig.1 (a-c) with the EDX analysis for the particles shown in Fig. (1-d). The charge was loaded in an electric furnace and heated up to $700^{\circ} \mathrm{C}$. After complete melting of the aluminum alloy, the temperature was brought down to the semi-solid state (slurry) $610^{\circ} \mathrm{C}$, and a mechanical stirrer was brought down in to the molten slurry shape rotating at a constant stirrer speed of $670 \mathrm{rpm}$. The $\mathrm{ZrO}_{2}$ nanoparticles were capsulated in an Al foil and preheated at $220^{\circ} \mathrm{C}$ for 3 hours in the electric furnace. The treated capsulate foil particles were added to the molten metal at constant rate to improve the wettability in the molten base metal, the stirring action was continued for 2 minutes to enable uniform distribution of the $\mathrm{ZrO}_{2}$ nanoparticles. The casting parameters were selected based on previous work by the authors [28-30].

After casting, the cast samples where machined and samples were taken from the castings and heat treated according to the specified heat treatment cycle. The heat treatment consisted of solution treatment at $\left(550^{\circ} \mathrm{C}\right.$ for 2 hours), followed by water quenching at $\left(25^{\circ} \mathrm{C}\right)$, the samples were then artificially aged at temperatures of $\left(170^{\circ} \mathrm{C} \& 180^{\circ} \mathrm{C}\right)$ for different ageing time durations $(2 \mathrm{hr} ., 4 \mathrm{hr} . \& 6 \mathrm{hr}$.).

\section{Specimen Preparation:}

Deferent samples of the cast and T6 heat treatment where prepared for microstructure and mechanical properties. The microstructure examination was carried out, using Olympus (BX41M-LED) optical metallurgical microscope linked to high-resolution digital camera with image analyzer software for microstructure analysis. The topography characteristics were studied using Scanning Electron Microscope SEM.JEOL (JSM-5500 LV) by applying high vacuum mode at $20 \mathrm{KV}$, after etching using diluted Keller's reagent of chemical composition (190 ml distilled water, $3 \mathrm{ml} \mathrm{HNo}, 5 \mathrm{ml} \mathrm{HCl}$ and $2 \mathrm{ml} \mathrm{HF}$ ) for $30 \mathrm{sec}$. The samples were coated by gold sputter coater (SPI-module) and were examined under X-ray micro-analyzer (Module Oxford 6587 INCA x- sight) attached to SEM after gold coating (ionization of the specimen by solution containing particles of gold).

The hardness tests were conducted on Rockwell Hardness Device,scale $\left(H_{R}\right)$. The load $100 \mathrm{Kg}$ (primary load $10 \mathrm{Kg}+$ additional load of $90 \mathrm{Kg}$ ) and (1/16)" diameter hardened steel ball, and initial time 10 second. The cast specimens were machined according to ASTM (B557M-060) standard with a gauge length of $36 \mathrm{~mm}$ and gauge diameter of $6 \mathrm{~mm}$ for tensile test. The tensile test was performed on Monsanto Company machine controlled by tonometer of mercury liquid with capacity $10 \mathrm{KN}$ at low constant rate (this device is manually operated), the reported results for each case was determined based on a minimum of three test specimens. 


\section{RESULTS AND DISCUSSION}

\section{Microstructural Observation of the Cast Samples}

The optical images, shown in Fig (2-a), illustrate the microstructure of the monolithic cast A356 and the A356/ $\mathrm{ZrO}_{2}$ nanoreinforced composites. It is shown from Fig (2-a), that the structure of the monolithic A356 Al alloy consist of a dendrite structure of eutectic Si \& Al phase consisting of globular grains and eutectic silicon phase. Equiaxed grains were observed after the nanoparticles addition to the matrix alloy, as shown in Fig (2-b). The SEM microstructure of the monolithic cast alloys is shown in Fig (3 a-b). The Al alloy consists of primary a phase (light regions) \& Al/Si eutectic structure (darker regions). Needle-like primary $\mathrm{Si}$ particles were also found to be distributed along the boundaries of the a-Al phase. The SEM micrographs of the A356 matrix alloy reinforced with capsulated $3 \% \mathrm{ZrO}_{2}$ particles is shown in Figs (3 cd), where, the presence of large grains of primary a-Al, flake lamellar Si and some random distribution of small clusters of $\mathrm{ZrO}_{2}$ particles having non-spherical shape is observed.

\section{Microstructure Observation of T6 Heat Treatment Specimens}

The microstructure of the monolithic cast A356 alloys before and after T6 heat treatment are shown in Fig 4 (a \& b). The structure of the monolithic A356 Al alloy consists of primary a phase (dark regions) \& Al/Si eutectic structure (lighter regions). Needle-like primary $\mathrm{Si}$ particles were also found to be distributed along the boundaries of the $\alpha$-Al phase. The morphology of the microstructure changed after heat treatment. The lamellar eutectic structure size phase was converted in to fine spheriodized Si particles uniformly distributed in Al the matrix. Similar results are reported in literature of semi-solid casting of A356 [21].

Also the microstructure of the A356/3\% $\mathrm{ZrO}_{2}$ alloys before and after $\mathrm{T} 6$ heat treatment are shown in Fig 5 ( $a \& b$ ). The morphology of the microstructure changed after the T6 heat treatment. The lamellar eutectic Si size phase was converted into fine spheriodized Si particles uniformly distributed in the Al matrix, which significantly improves the mechanical properties. Soaking the alloy at a temperature near the eutectic temperature sufficient to dissolve the hardening elements ( $\mathrm{Si}, \mathrm{Mg}$ ) and enhances the distribution and leads to refinement of the eutectic silicon particles.

The microstructure of the A356 matrix alloy reinforced with capsulated $3 \% \mathrm{ZrO}_{2}$ particles aged for a variety of time lengths are shown in Fig 6 (b-d) were, specimen (a) non- heat-treated consists of primary a phase (dark regions) \& Al/Si eutectic structure (lighter regions), and needle-like primary Si particles. Specimens (b-d) heattreated at aging temperature $170^{\circ} \mathrm{C}$ at different aging time lengths (2hr, $\left.4 \mathrm{hr} \& 6 \mathrm{hr}.\right)$. It is shown from the figure that the microstructure features of the Al-Si-Mg alloy improved with ageing time and the microstructures exhibited periodization of the silicon flakes into fine structures, which account for the improved mechanical properties. The effect of heat treatment on fragmenting and spherodising the Si particles has been explained to be related to the presence of $\mathrm{Mg}(0.213 \%$ in this alloy Table 1), where the following precipitation sequence was described: (i) aluminum supersaturated solid solution; (ii) cluster of Si and Mg atoms; (iii) dissolution of $\mathrm{Mg}$ cluster and formation of $\mathrm{Mg} / \mathrm{Si}$ co-cluster (GP-zone; (iv) formation of Mg2Si stable plates. 


\section{Effect of Artificial Ageing Temperature and Ageing Time on Hardness}

The variation in the hardness of the monolithic $\mathrm{A} 356$ alloy and $\mathrm{A356} / 3 \% \mathrm{ZrO}_{2}$ nanoreinforced alloy is shown in Table 2 and Fig 7 at different ageing (temperature \& time). It is observed that the addition of nanoparticles resulted in higher hardness than the monolithic $A 356$ alloy. The maximum hardness after $4 \mathrm{hrs}$ aging at $170^{\circ} \mathrm{C}$ is (70 HRB), and the increase in the hardness of the heat treated sample has been correlated with the formation, development and growth of the GP zones [28]. Other work has attributed the increase in hardness to the harder and stronger interfacial bonding strength of the spherodised eutectic $(\mathrm{Si}$ and $\mathrm{Mg}$ ) phase after $\mathrm{T6}$ heat treatment [22]. The increase in the hardness is due to the formation of the GP zones. The decrease in the hardness after reaching the peak results from a transformation of the GP zones into an intermediate metastable phase due to over aging, which decreases the hardness after a certain time [23, 24]. The results also demonstrates that, longer ageing times lead to over ageing which results a decrease in the mechanical properties such as hardness and impact energy [25].

\section{Effect of (T6) Heat Treatment on Tensile Strength and Hardness of A356 Alloy}

Tensile test samples were machined from the aged castings at $\left(170^{\circ} \mathrm{C}\right.$ for $4 \mathrm{hrs}$.) and tested for each alloy, the results of which are shown in Table 3 and Fig 8 . It is clearly observed that higher strength values were achieved after heat treatment. The UTS increased from (119 to167 MPa) for the monolithic alloy and from (165 to198MPa) for the $\mathrm{A} 356 / 3 \% \mathrm{ZrO}_{2}$ Alloy. This increase in strength after heat treatment can be explained by the dislocation theory, as the precipitated particles act as an obstruction to the motion of the dislocation and provide resistance to the motion of the dislocations, leading to increase in the tensile strength [26].

Generally, the tensile properties of the Al-Si-Mg alloy improved with ageing time until it reached the peak ageing time i.e. from( 2-4 hr.), afterwards it dropped after between 4-6 $\mathrm{h}$ ageing time. This is attributed to the continuous increase in the breakdown (over ageing), the structure of the Si eutectic network formed with grain refinement as the ageing continued, which explains the decrease in the strength of the alloy.

Figure 9 shows the average \% elongation of the samples which were aged at $\left(170^{\circ} \mathrm{C}\right.$ for $4 \mathrm{hrs}$.). It's clearly observed, that the \% elongation increased after heat treatment, from (4.5 to $4.9 \%$ ) for the monolithic alloy and from (4.7 to 6.4) for the $A 356 / 3 \% \mathrm{ZrO}_{2}$ reinforced alloy. This result is due to increase in ductility of the alloy after heat treatment resulting from the periodization of the silicon crystals because the stress required for nucleating avoid or crack at a particle matrix interface would increase for this morphology.

Figure 10 shows the hardness of the samples after ageing at $\left(170^{\circ} \mathrm{C}\right.$ for $4 \mathrm{hrs}$.). It's clearly observed that the higher hardness is achieved after heat treatment. The hardness increased from ( 23 to $52 \mathrm{HRB}$ ) for the monolithic alloy and from (60 to 70 HRB) for the $A 356 / 3 \% \mathrm{ZrO}_{2}$ reinforced alloy. The hardness of the heat-treated samples increased because harder and stronger interfacial bonding strength of the eutectic phase was retained after T6-heat treatment. T6-heat treatment provides hardening by precipitation of constituents from the solid solution. The Precipitation of these constituents occurs during the artificial aging step. The sharp edge fiber 
eutectic Si transforms into spheriodized eutectic Si embedded in the homogeneous a- Al matrix. The precipitated constituents are believed to account for the increase of hardness [26].

The previous results show that the introduction of $3 \% \mathrm{ZrO} 2$ nanoparticles resulted an enhancement in the tensile strength and the ductility after heat treatment. During the solidification process the changes are caused by the difference of the coefficients of thermal expansion in the primary phase of composites as matrix (aluminum or silicon) and the introduction of nanoparticles as reinforcement secondary phase resulted enhancement in the hardness. The coefficients of thermal expansion of the primary matrix phase such as aluminum and silicon and the ceramic material reinforcement $\mathrm{ZrO} 2 \mathrm{TiO} 2$ nanoparticles have different values: for the primary phase $\left(22.2 \times 10^{-6}\right.$ $1 / \mathrm{K})$ for aluminum, and $\left(3 \times 10^{-6} 1 / \mathrm{K}\right)$ for silicon and $\left(6.53 \times 10^{-6} / \mathrm{K}\right)$ for $\mathrm{ZrO} 2$ nanoparticles. Additionally, when the nano particles are present in the matrix alloy, these particles lead to increased dislocation density generation. The dislocation density increase helps or contributes to the increased hardness of the aluminum phase. The increase in the hardness is due to the mismatch or difference in the thermal expansion and difference in elastic moduli of the nanoparticles also. The addition of the nanoparticles results in restriction in the plastic flow of matrix, where the constrain in the plastic flow is because the inter-particle distance is smaller and that results increase in the flow stress. This is according to the classical theory for dispersed strengthening in forming composites, which explains that the role of dispersed nanoparticles is to constrain the motion of the dislocations by the precipitates and the dispersoid particles in the matrix. These particles are coherency strains and the all dislocations gather networks around them, this is due to a misfit between the reinforcement particles and the matrix alloy, this misfit causes the increase in strength and hardness.

\section{CONCLUSIONS}

Based on the results presented in this study, the following conclusions may be drawn:

1- Applying the T6 heat treatment to cast $\mathrm{A} 356$ alloy with and without $\mathrm{ZrO}_{2}$ nanoparticles addition results in changes in the microstructure of the alloy, were the Si flakes become refined and spheriodized, resulting improvement in the mechanical properties.

2- The optimum heat treatment achieved in this work is by solution treatment at $550^{\circ} \mathrm{C}$ and aging at $170^{\circ} \mathrm{C}$ for $4 \mathrm{hrs}$.

3- The hardness of the specimens increase with increase in ageing time from 2-4 hrs. reaching a value of $52 \mathrm{HRB}$ for the monolithic alloy and $70 \mathrm{HRB}$ for the nanoreinforced alloy, and decrease with increase in aging time from 4-6 hrs.

4- The T6 heat treatment is more effective on hardening the monolithic A356 alloy (23-52 HRB), compared to the nanoreinforced alloy (60-70 HRB).

5- The T6 heat treatment is more effective on strengthening the monolithic A356 alloy (119-167 MPa), compared to the nanoreinforced alloy (165-198 MPa).

6- The T6 heat treatment is more effective on enhancing the ductility of the nanoreinforced alloy (4.7-6.4\%), compared to the monolithic A356 alloy (4.5$4.9 \%)$. 


\section{REFERENCES}

[1] Chuang, Y. Lee, S. and Lin, H., Materials Transactions, 47(1), 106, (2006).

[2] Abdulwahab, M. , Madugu, I. A., Yaro, S.A., Hassan, S. B., Popoola, A. P. I. Mater Des, 32(3) , 1159, (2011).

[3] Li, H. X., Rudnev, V. S., Zheng, X. H., Yarovaya, T. P., Song. R. G., Journal of Alloys and Compounds, 462, 99,(2008).

[4] Rudman, K. B. "Metal Casting Reference Book", Department of Materials Science and Engineering, Michigan Technical University, USA, pp. 23-29, (2005).

[5] Ding, H., Zhou, G. And Hui, D.,"Frictional and wear performance of an aluminum alloy in artificial seawater". Proceeding of the Institute of Mechanical Engineers (Proc. IMechE), Part J: Engineering Tribology, 225: pp. 43-49, (2011).

[6] Thompson, S., Cockcroft, S. L., Wells, M. A., J "Mater Sci Techn", 20, 194, (2004).

[7] S. A. kori, B. S. Murty and M. Chakraborty, "Preparation and characterization of $\mathrm{Al}-\mathrm{B}$ and B-rich Al-Ti-B master alloys for the grain refinement of $\mathrm{Al}-7 \mathrm{Si}$ alloy", AFS transactions, 109, pp 267-286, (2001).

[8] D. L. Zhang and L. Zheng, "The quench sensitivity of cast Al-7 wt. \%Si-0.4 wt. \% Mg alloy", Metallurgical and Materials Transactions A, 27, pp3983-3991, (1996).

[9] S. A. Kori, B. S. Murty, M. Chakraborty, "Development of an effi cient grain refi near for Al-7Si alloy". Materials Science and Engineering A, 280, pp 58-61,(2000).

[10] P. S. Mohanty, J. E. Gruzleski, "Mechanism of grain refi nement in aluminum", Acta Metallurgical et Materialia, 43, pp 2001-1012 (1995).

[11] S. P. Ringer, K. Hono, Mater. Charact. Vol. 44, pp 101-131, (2000).

[12] D. Sun, X. Sun, D. O. Northwood, J. H. Sokolowski, Mater. Charact. Vol.36, pp 83-92, (1996).

[13] Murali, S.; Raman, K.S.; Murthy, K.S.S. The formation of -phase and Be-Fe phases in Al-7Si-0.3M alloy containing Be. Mater. Sci. Eng. A 190, pp165172, (1995).

[14] Kammer, C. Aluminum Handbook, Vol. 1:" Fundamentals and Materials; Aluminum-Verlag Marketing and Communication": Dusseldorf, Germany, (1999).

[15] Han, Y.; Samuel, A.M.; Doty, H.W.; Valtierra, S.; Samuel, F.H. "optimizing the tensile properties of Al-Si-Cu-Mg 319-type alloys: Role of solution heat treatment". Mater. Des. 58, pp 426-438,(2014).

[16] D. Apelian, S. Shivkumar, G. Sigworth, "Fundamental Aspects of Heat Treatment of Cast Al-Si-Mg Alloys", AFS Transactions, 97, pp 727-742,(1989).

[17] H. Abu Ei-Aini, K. Mohamed and Y. Hassan Mohammed, "Effect of mold types and cooling rate on mechanical properties of Al alloy 6061 within ceramic additives", The 2nd International Conference on Energy Engineering ICEE-2, pp 27-29,( 2010).

[18] G. Mrwka-Nowotnik, J. Sieniawski and M. Wierzbiska, "Analysis of intermetallic particles in AISi1MgMn aluminum alloy", Journal of Achievements in Materials and Manufacturing Engineering, 20, pp155-158, (2007).

[19] E.Ogris, A. Wahlen, H. Luchinger and P. J. Uggowitzer, "On the silicon spheroidization in Al-Si alloys", Journal of Light Metals, 2, pp263-269, (2002). 
[20] L. Lasa and J. M. Rodrigues-lbade, "Wear behaviour of eutectic and hypereutectic Al-Si-Cu-Mg casting", American Journal of Engineering Research (AJER), (2016).

[21] S. C. Wang, M. J. Starink, "Precipitates and intermetallic phases in precipitation hardening $\mathrm{Al}-\mathrm{Cu}-\mathrm{Mg}-(\mathrm{Li})$ based alloys", International Materials Reviews, 5,pp 193-215, (2005).

[22] Raj Kumar Singh, Amit Telang, S. Das, "Microstructure and Mechanical Properties of Al-Si Alloy in As-cast and Heat Treated Condition", American Journal of Engineering Research (AJER), pp 133-137, (2016).

[23] S. Manasijevic,"Aluminum piston alloys", LOLA Institute, Belgrade, (2012).

[24] R. X. Li, R. D. Li, L. Z. He, C. X. Li, H. R. Gruan, Z. Q. Hu," Age hardening behavior of cast Al-Si base alloy", materials Letters, 58, pp 2096-2101, (2004).

[25] M. Abdulwahab, I. A. Madugu, F. Asuke, O.S.I. Fayomi, F. A. Ayeni," Effect of thermal ageing treatment $O$ mechanical properties of antimony-modified A356.0-type Al-Si-Mg Alloy", J. Mater. Environ. Sci.4, pp 87-92, (2013).

[26] L.Y.Pio,"Effect T6 heat treatment on the mechanical properties of gravity die cast A356 aluminum alloy", journal of applied science (11),pp 20482052,(2011).

[27] I.S. El- Mahallawi, Y.Shash, K. Eigenfeld, T.S. Mahmoud, R.M. Ragaie, A.Y.Shash and M.A.El Saeed: "Influence of Nanodespersions on Strengthductility properties of semisolid cast Al Alloy", Material Science and Technology, Vol 26 (10), (2010).

[28] I. El-Mahallawi, H. Abdelkader, L. Yousef, A. Amer, J. Mayer, A. Schwedt.: "Influence of $\mathrm{Al} 2 \mathrm{O} 3$ nano-dispersions on microstructure features and mechanical properties of cas and T6 heat-treated Al Si hypoeutectic Alloys", Materials Science \& Engineering A 55 pp 76-87, (2012).

[29] I.S.El Mahallawi, ahmed.Y. Shash, 'The Effect of Process Parameters on the Mechanical Properties of A356 Al-Alloy/ZrO2 Nano-composite". Journal, of Nano ResearchVol. 38, pp. 1-8, (2016) .

[30] I. S. El-Mahallawi, A. Y. Shash, and A. E. Amer," Nano reinforced Cast Al-Si Alloys with Al2O3, TiO2 and ZrO2 Nanoparticles", Metals, pp 802-821. (2015)

[31] H. Tiwery, W. Hoziefa, Adel B. El-Shabasy ,I. El-Mahallawi, "Effective Nanoparticles Feeding Treatment in Casting of A356/ZrO2 Nano-Reinforced Composite", The Minerals, Metals \& Materials Society 2018 O. Martin (ed.), Light Metals 2018, The Minerals, Metals \& Materials Series, https://doi.org/10.1007/978-3-319-72284-9_144. 


\section{TABLES AND FIGURES}

Table 1. Chemical Composition of the A356 Alloy.

\begin{tabular}{|c|c|c|c|c|c|c|c|}
\hline \multicolumn{7}{|c|}{ Element composition (wt. \%) } \\
\hline $\mathrm{Si}$ & $\mathrm{Cu}$ & $\mathrm{Mg}$ & $\mathrm{Fe}$ & $\mathrm{Mn}$ & $\mathrm{Zn}$ & $\mathrm{Ti}$ & $\mathrm{Al}$ \\
\hline 7.511 & 0.049 & 0.213 & 0.620 & 0.053 & 0.039 & 0.049 & Bal. \\
\hline
\end{tabular}
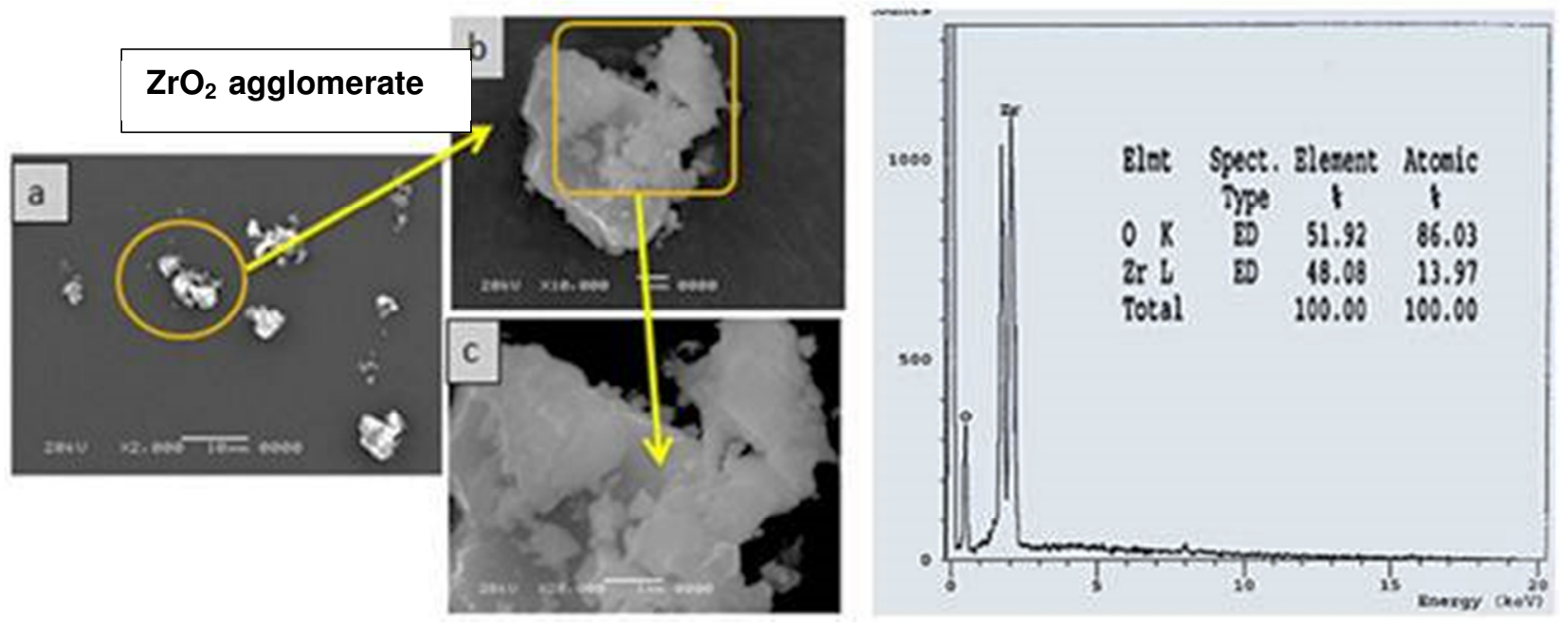

Fig. 1. SEM micrographs of (30nm) $\mathrm{ZrO}_{2}$, at (a) X2000 (b) $\mathrm{X} 10000$ (c) $\mathrm{X} 20000$, Magnificent spectrum $\mathrm{ZrO}_{2}$ particle and EDX analysis of $\mathrm{ZrO}_{2}$ nanoparticles.
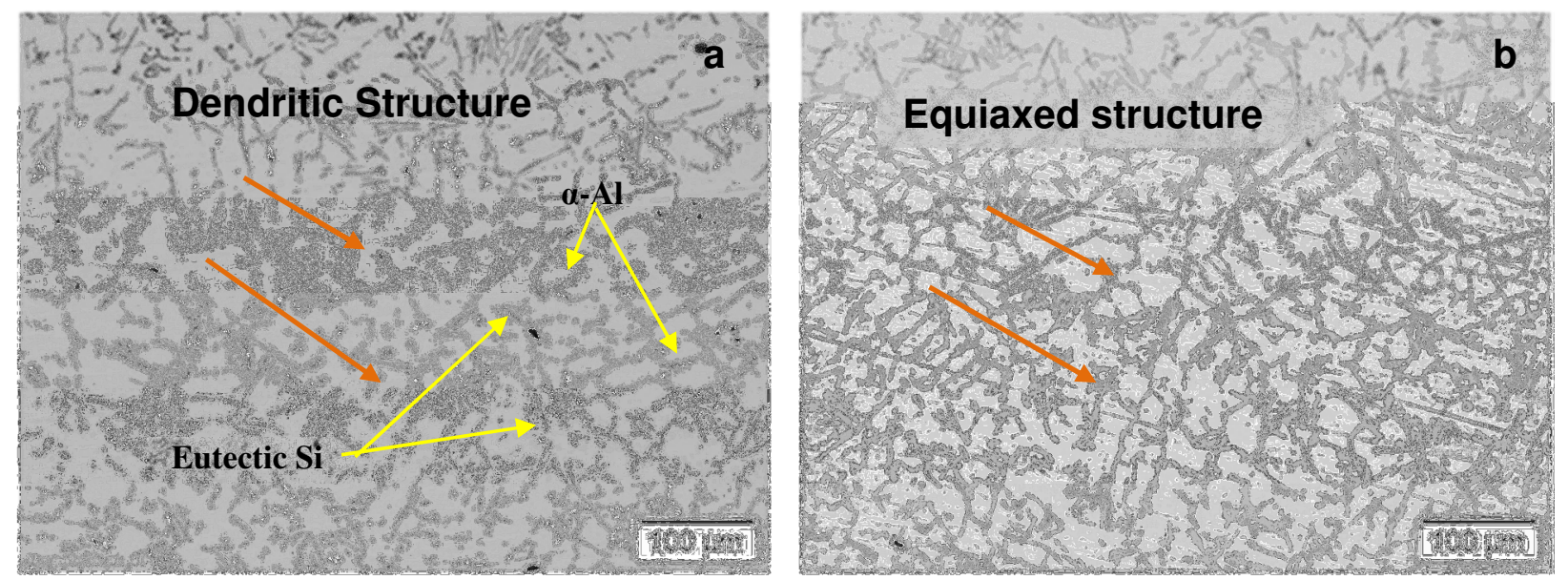

Fig. 2 Optical micrographs of A356 aluminum alloy as cast alloy from the liquid state at $700{ }^{\circ} \mathrm{C}$ (a) \& $\mathrm{A} 356 / 3 \% \mathrm{ZrO}_{2}$ cast from the semi-solid state at $610^{\circ} \mathrm{C}$ (b) capsulate Feeding at $\mathrm{X} 100$ magnification. 

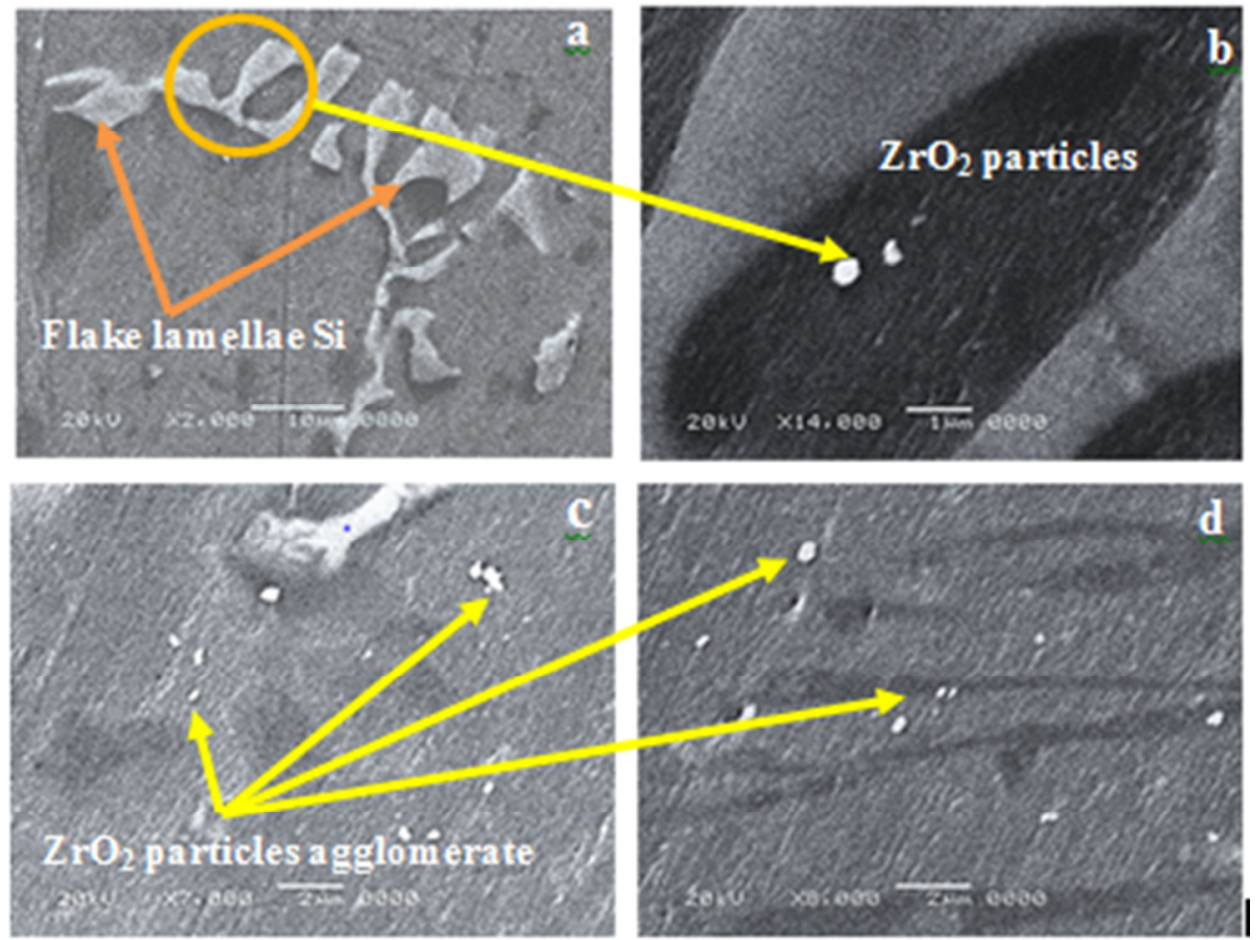

Fig 3. SEM Micrograph of cast A356, flake lamellar eutectic Si \& $\alpha-A l$ phase at $700{ }^{\circ} \mathrm{C}$ (a) $X 700$, (b) X2200, SEM Micrograph of the micro structure of (A356/3\% $\mathrm{ZrO}_{2}$ ) semi solid treated at $610^{\circ} \mathrm{C}$, non-homogenous distribution of the particles and clustering and agglomeration $\mathrm{ZrO}_{2}$ particles within the matrix alloy at (c) X7000, (d) X8000 magnification.
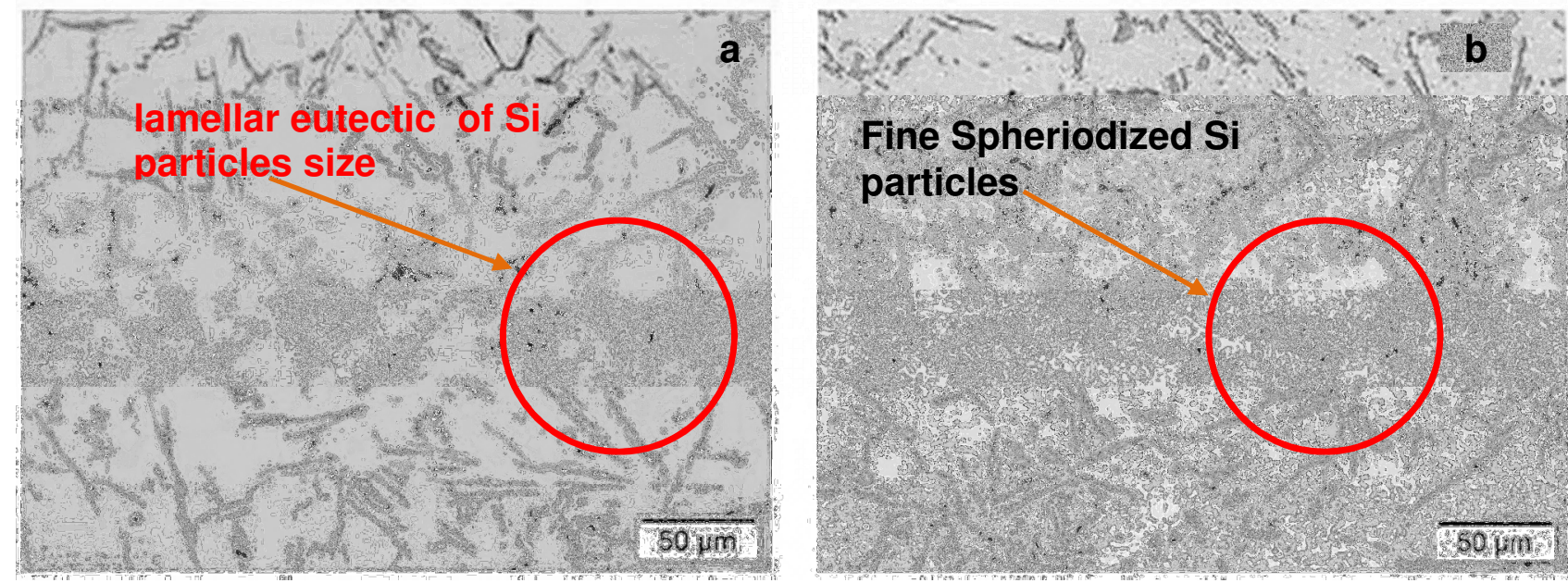

Fig .4 Microstructure of the monolithic cast specimen (a) non heat-treated A356 (b) T6 heat- treated $\mathrm{A} 356$ aged at $\left(170^{\circ} \mathrm{C}\right.$ for $4 \mathrm{hrs}$.). Magnification at X200. 

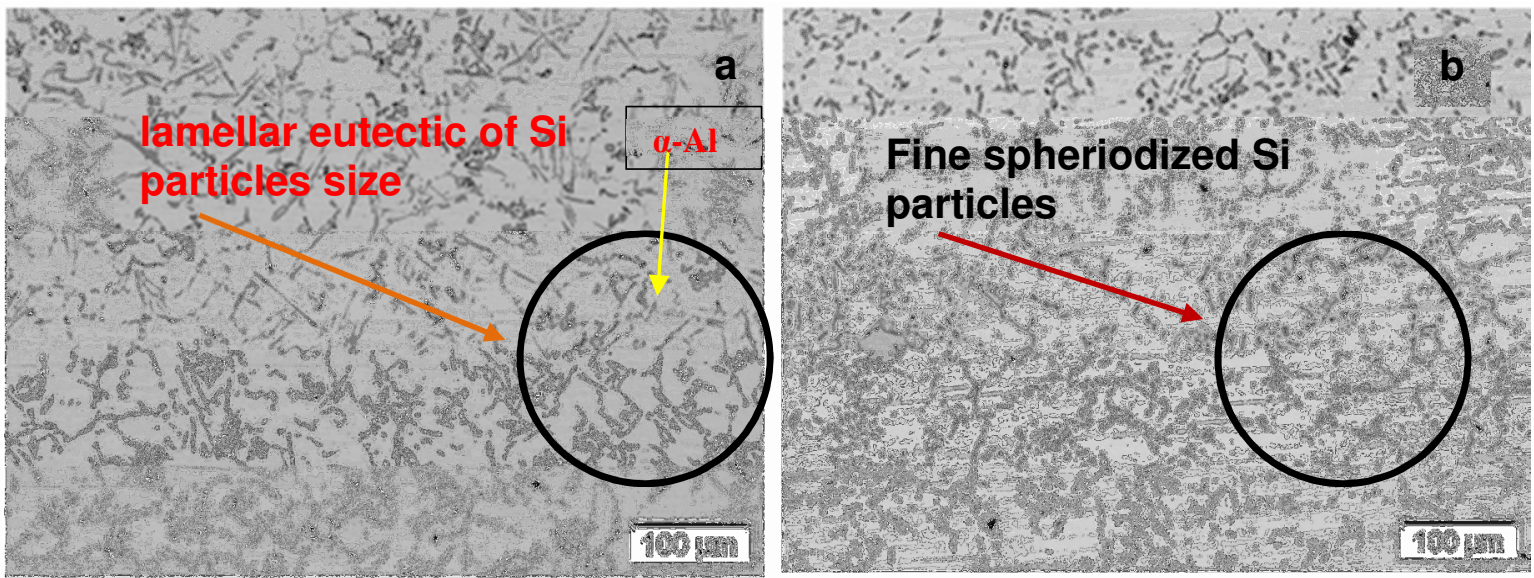

Fig .5 Microstructure of $3 \% \mathrm{ZrO}_{2}$ specimen (a) non heat-treated A356, (b) T6 heattreated $\mathrm{A} 356$ aged at $\left(170^{\circ} \mathrm{C}\right.$ for $4 \mathrm{hrs}$.). Magnification at X100.
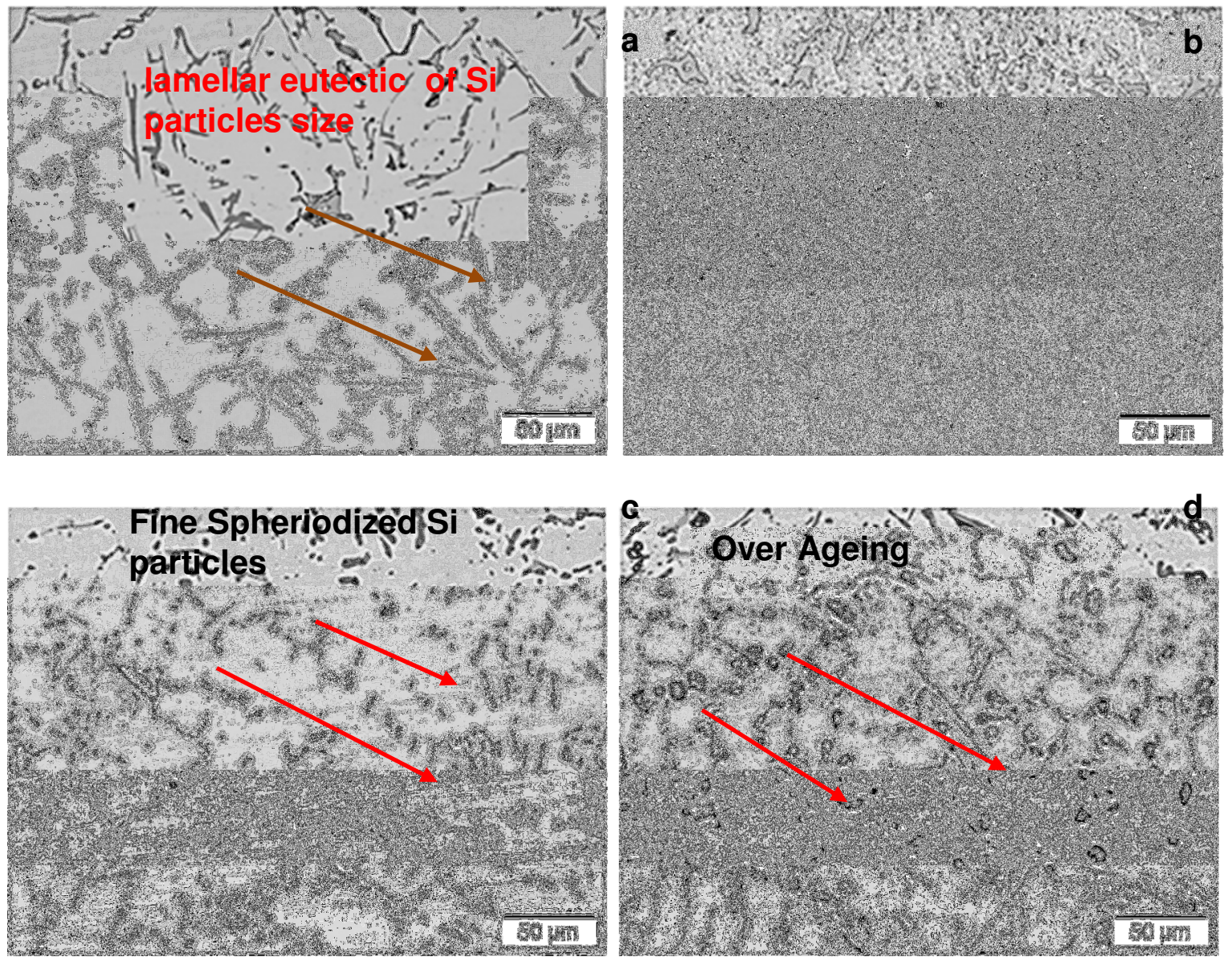

Fig. 6 Microstructure of specimen (a) non heat-treated A356 alloy (a), and of $3 \% \mathrm{ZrO}_{2}$ aged at $\left(170^{\circ} \mathrm{C}\right.$ for $\left.2 \mathrm{hrs}\right)(\mathrm{b})$, aged at $\left(170^{\circ} \mathrm{C}\right.$ for $\left.4 \mathrm{hrs}\right)(\mathrm{c})$, aged at $\left(170^{\circ} \mathrm{C}\right.$ for $\left.6 \mathrm{hrs}\right)(\mathrm{d})$. Magnification atX200. 
Table2. Effect hardness (HRB) after Heat Treatment (T6) on Age Hardening of A356 Alloy

\begin{tabular}{|c|c|c|c|c|c|c|}
\hline \multirow{2}{*}{$\begin{array}{c}\text { Temperature } \\
\left.\text { Aging( }{ }^{\circ} \mathrm{C}\right)\end{array}$} & \multicolumn{4}{|c|}{ As casted } & \multicolumn{3}{c|}{$\begin{array}{c}\text { As 3\%ZrO } \\
\text { pano } \\
\text { particles }\end{array}$} \\
\cline { 2 - 7 } & \multicolumn{3}{|c|}{ Time Aging(hr.) } & \multicolumn{3}{c|}{ Time Aging(hr.) } \\
\cline { 2 - 7 } & $\mathbf{2 h r}$. & $\mathbf{4 h r}$. & $\mathbf{6 h r}$. & $\mathbf{2 h r}$. & $\mathbf{4 h r}$ & $\mathbf{6 h r}$. \\
\hline $170^{\circ} \mathrm{C}$ & 35 & 52 & 48 & 62 & 70 & 55 \\
\hline $180^{\circ} \mathrm{C}$ & 29 & 44 & 40 & 59 & 62 & 45 \\
\hline
\end{tabular}

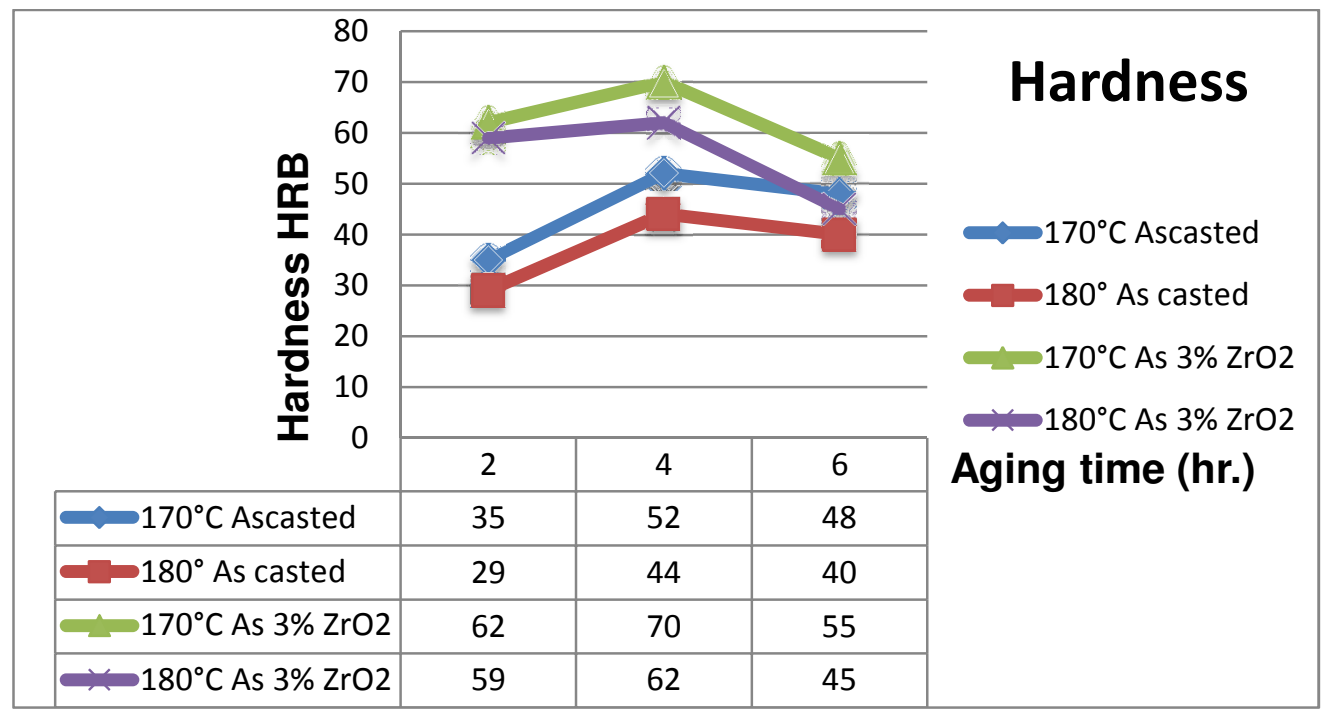

Fig. 7 Effect of hardness (HRB) after (T6 heat treatment) aging at $\left(170^{\circ} \mathrm{C} \& 180^{\circ} \mathrm{C}\right)$ ofcast $\mathrm{A} 356$ \& $\mathrm{A} 356 / 3 \% \mathrm{ZrO}_{2}$, aging time (2hr, 4hr\&6hrs).

Table 3. Mechanical properties of $\mathrm{A} 356.0$ before \& after treatment.

\begin{tabular}{|c|c|c|c|}
\hline Condition & UTS(MPa) & \%Elongation & Hardness(HRB) \\
\hline $\begin{array}{c}\text { As cast before } \\
(\mathrm{T} 6)\end{array}$ & 119 & 4.5 & 23 \\
\hline $\begin{array}{c}\text { As 3\% } \mathrm{ZrO}_{2} \text { before } \\
(\mathrm{T} 6)\end{array}$ & 165 & 4.7 & 60 \\
\hline $\begin{array}{c}\text { As cast after } \\
(\mathrm{T} 6)\end{array}$ & 167 & 4.9 & 52 \\
\hline $\begin{array}{c}\text { As 3\%ZrO} \\
(\mathrm{T} 6)\end{array}$ & 198 & 6.4 & 70 \\
\hline
\end{tabular}




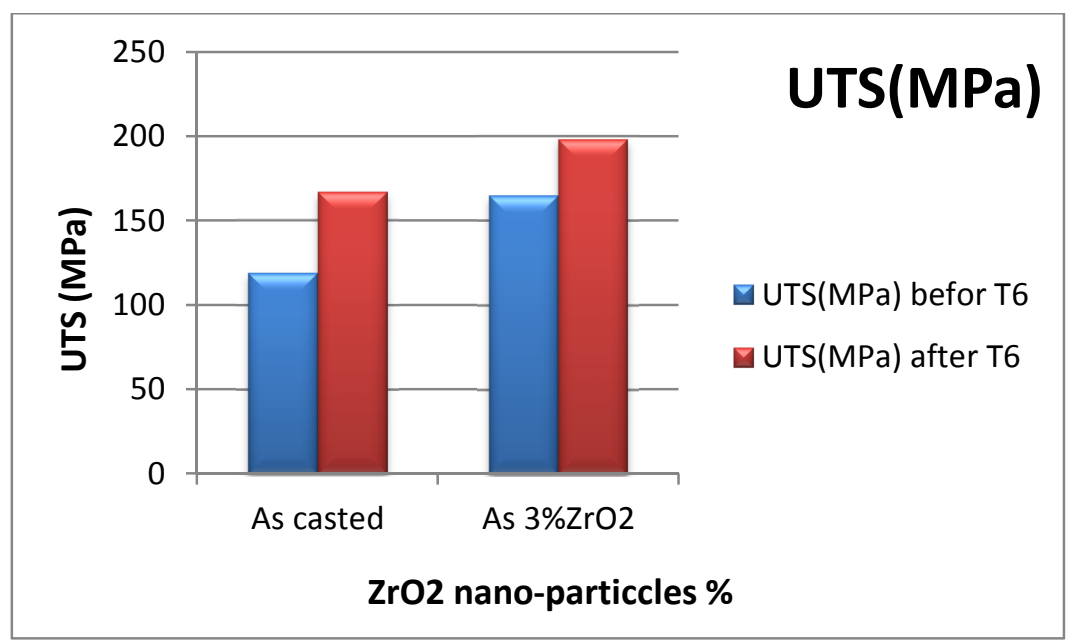

Fig 8. Change in UTS with nanoparticles addition before and after T6 heat treatment.

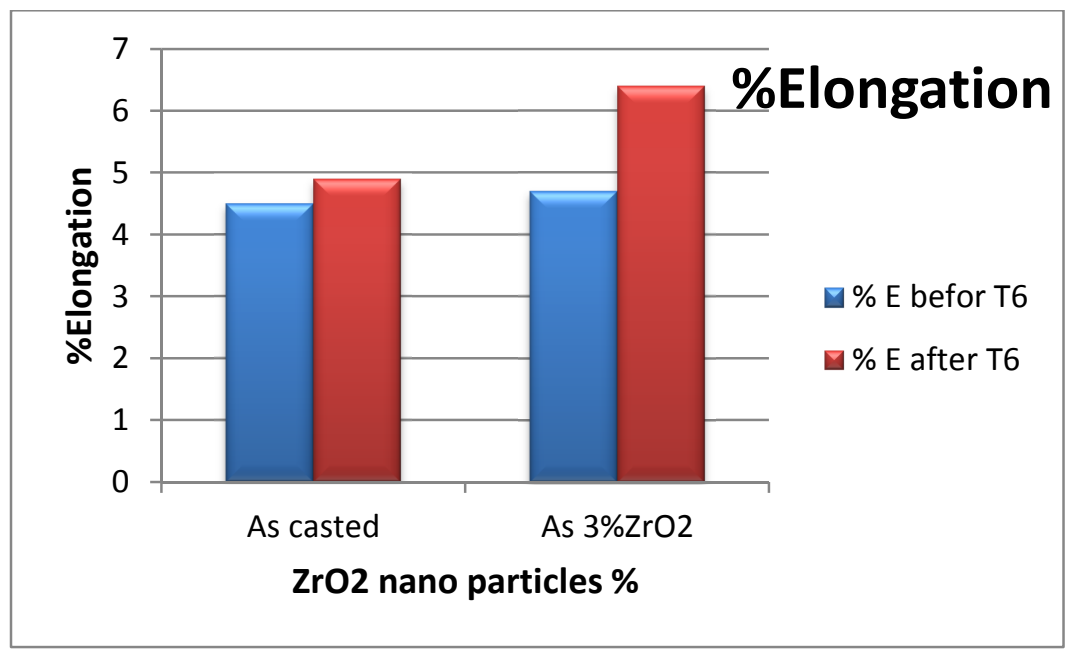

Fig.9 Change in elongation\% with nano particles addition before and after T6 heat Treatment.

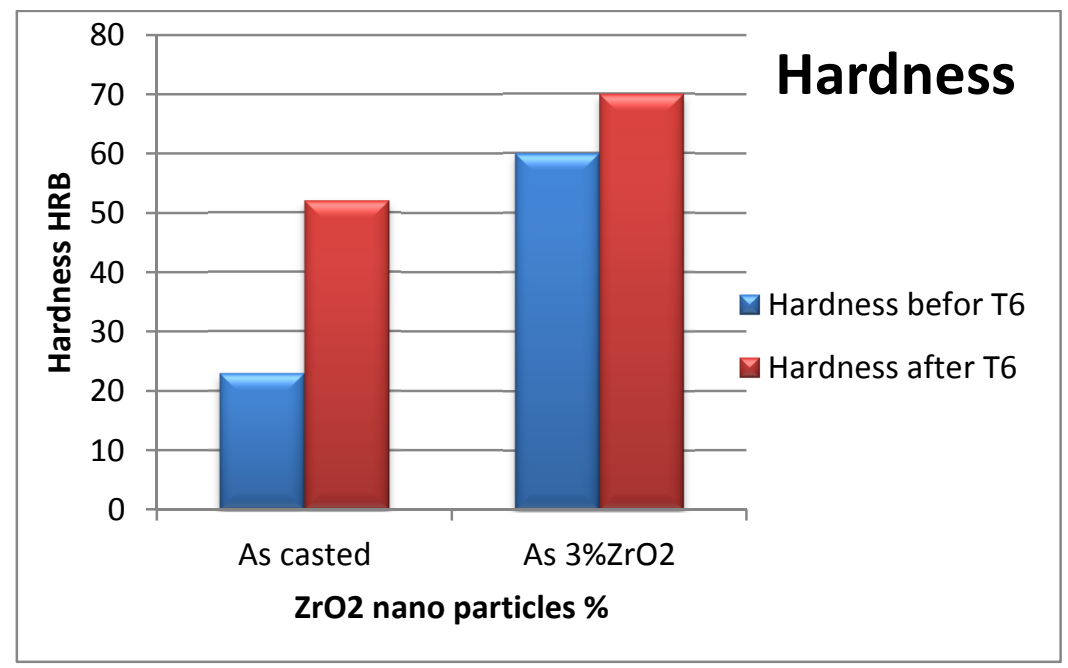

Fig.10 Change in Hardness with nanoparticles addition before and after T6 heat treatment. 